\title{
Overarching principles and salient findings for inclusion in guidelines for power mobility use within residential care facilities
}

\author{
William B. Mortenson, BScOT, MSc; ${ }^{1-2 *}$ William C. Miller, PhD, OT; ${ }^{1-3}$ Jeanette Boily, BScOT; $^{1}$ \\ Barbara Steele, BScOT; ${ }^{\mathbf{1}}$ Erin M. Crawford, BScOT; ${ }^{\mathbf{1}}$ Guylaine Desharnais, BScOT $^{\mathbf{1}}$ \\ ${ }^{1}$ Vancouver Coastal Health Authority, Vancouver, British Columbia, Canada; ${ }^{2}$ School of Rehabilitation Sciences, \\ University of British Columbia, Vancouver, British Columbia, Canada; ${ }^{3}$ International Collaboration of Repair \\ Discovery, Vancouver, British Columbia, Canada
}

\begin{abstract}
Although power mobility has many potential benefits for users, power mobility incidents and accidents are a serious concern. To date, little research has explored power mobility safety, and no gold standard exists to determine whether the user is a safe driver. As a possible alternative to a facility unilaterally imposing regulations on power mobility users, we conducted a research project in which power mobility users and other stakeholders used the Delphi method to develop guidelines for power mobility use within a residential facility setting. This article presents the overarching principles for power mobility use and noteworthy items from the safety guidelines that participants developed. These findings highlight the safety issues that are encountered in residential care settings and suggest some strategies to deal with them.
\end{abstract}

Key words: assistive technology, client-centered practice, Delphi method, geriatrics, long-term care, mixed methods, power mobility safety, practice guidelines, risk, safety.

\section{INTRODUCTION}

Although not a panacea for all individuals with disabilities, power mobility offers a wide range of potential benefits. For some individuals, power mobility means independence within a facility setting and/or in the community, because using it enhances functional capability and offers opportunities for increased access to the environment [1-4]. Other advantages of power mobility use include increased opportunity for socialization, role enablement, and increased participation in desired activities [1-2,5].

\section{Prevalence of Use}

Given the advantages of power mobility and improvements in the technology, power mobility use is expected to increase in the future [6]. Reed et al. estimated that 5 percent of residents of long-term care facilities used power mobility [7]. An unpublished survey (June 2000) within the Vancouver Coastal Health Authority (VCHA) indicated that power mobility use ranged between 3.3 to 55 percent in three residential care facilities. In 2003, an estimated 660,000 power mobility users resided in the United States and that the majority of these individuals were over age 65 [8]. Since the number of people 65 years and older is expected to almost double in the next 25 years [9], the number of people in institutional care and the use of power mobility will likely increase. Use of power mobility within institutional settings is therefore also likely to increase.

Abbreviation: VCHA = Vancouver Coastal Health Authority. ${ }^{*}$ Address all correspondence to William B. Mortenson, BScOT, MSc; School of Rehabilitation Sciences, University of British Columbia, T325-2211 Westbrook Mall, Vancouver, BC Canada V6T 2B5; 604-714-4108; fax: 604-8227624. Email: bmortens@interchange.ubc.ca

DOI: 10.1682/JRRD.2005.01.0031 


\section{Accidents}

Although the prevalence of power mobility accidents is difficult to ascertain, such accidents are a serious concern within residential facilities. In the United States, from 1991 to 1992, an estimated 36,559 nonfatal wheelchair accidents were reported that were serious enough to require medical attention [10]. Unfortunately, the specific statistics for accidents resulting from power mobility were not delineated. However, Frank et al. found that, within 4 months of power mobility provision, 13 percent of those surveyed (15 out of 113) reported mishaps, which included tipping from chairs and falling while transferring [3]. In residential facility settings, many factors contribute to accidents, including declining abilities, resulting from progressive neurological diseases such as multiple sclerosis or Lou Gehrig's disease; the influence of medication, drugs, or alcohol; the high number of wheelchair users; crowding; and decreased physical and cognitive abilities of other residents. In an affiliated facility of one of the authors, 16 incidents of property damage resulting from power mobility use were reported from July 1999 to July 2000. This number is likely an underestimate, for only serious incidents were recorded. Within VCHA, power mobility incidents have also been reported that have caused automobile accidents and injuries involving worker's compensation claims.

\section{Power Mobility Conundrum}

Power mobility prescribers frequently encounter a dilemma in the assessment and prescription of power mobility. As therapists working in this area, we have noted an expectation for prescribers to prevent all power mobilitycaused personal and property damage. Townsend has described this as "risk management" [11]. This expectation creates a predicament for therapists, whose mandate of client-centered practice suggests that clients be allowed to participate in acceptable risk taking [12]. Prescribers in longterm-care settings therefore experience a tension resulting from their desire to facilitate independence while simultaneously ensuring safety for the users and those around them.

Although two standardized power mobility assessments have been developed, the Power-Mobility Indoor Driving Assessment [6] and the Power-Mobility Community Driving Assessment [13], neither assessment is intended to be used to determine whether a client is or will be a safe driver. "[These] assessments have been developed with an explicit a priori statement that they were not designed to assist the health care professional in deciding whether or not someone should have access to power mobility but rather to assist professionals and drivers in determining particular areas where driver training, device adaptation, and/or environmental modification would be indicated" [13, p. 124]. Thus, these instruments are not intended to indicate when risk becomes untenable.

Without a method to reliably determine when power mobility use becomes unsafe, prescribers within facility settings are frequently put in a difficult situation. Acting solely upon personal clinical judgment, therapists are expected to (1) police existing users for any safety concerns, (2) determine the cause of any incidents, (3) intervene appropriately to prevent future safety concerns, and (4) ensure corrective measures are carried out. Such actions may conflict with client-centered practice, which is defined as a therapeutic approach that "embraces a philosophy of respect for, and partnership with, people receiving services. Client-centered practice recognizes the autonomy of individuals [and] the need for client choice in making decisions" [14, p. 124].

To deal with power mobility safety issues, many facilities have developed guidelines and tools to aid in decision making [15]. Despite the existence of these tools, Mortenson et al. report that power mobility safety measures are seen as arbitrary, inconsistent, and poorly operationalized, and do not reflect the perspective of users [16], suggesting that the tools are largely deemed ineffective.

Given the lack of appropriate guidelines for determining when driving becomes unsafe and the researchers' commitment to the philosophy of client-centered practice [10,17-18], a two-phase research project was conducted with approval from VCHA and the local university ethics board with the following objectives:

1. Explore driver and nondriver perceptions of power mobility safety within three residential facilities.

2. Involve power mobility users and other stakeholders in the development of guidelines to address power mobility safety issues within these facilities.

This article, which addresses the second phase of the study, describes the overarching principles of how to deal with power mobility safety issues and interesting guideline items that were identified during this project. This information is important because it (1) highlights many power mobility safety issues that may be encountered within residential-care facilities, (2) may be helpful for anyone attempting to develop similar guidelines, and (3) may provide insight into future areas of study aimed at understanding and improving power mobility safety. 


\section{METHODS}

The Delphi method is a technique used to reach consensus on complex or contentious issues that require subjective interpretation [19-20]. In this multiple-stage process, participants are given iterative questionnaires that are developed based on information derived from previous questionnaires [19-20]. Generally, the first questionnaire is relatively open-ended, the second questionnaire allows participants to rank responses generated in the first round and, in additional questionnaires, participants may rerank these responses based on descriptive statistics from the second questionnaire. Such a technique has been suggested as one method for developing clinical practice guidelines [21] and, in the absence of higher levels of evidence, was chosen as the method for guideline development in this study.

\section{Participant Selection}

Our intention was to recruit participants from nine stakeholder groups from the three residential facilities included in the study. Facility 1 had a younger population (average age of residents $=56$ ) with a large number of power mobility users (58\%, or 82 out of 142 residents). Facilities 2 and 3 were multifloor, predominantly geriatric (average age of residents $=80$ and 82, respectively), approximately 200-bed, long-term-care facilities with a small number of power mobility users $(3 \%-5 \%$ of residents).

We initially targeted one participant from each facility for each stakeholder group. The nine stakeholder groups were (1) power mobility users with progressive conditions, (2) power mobility users with other nonprogressive conditions, (3) family members of residents who did not use power mobility, (4) family members of power mobility users, (5) nurses, (6) resident-care aids, (7) residents who did not use power mobility, (8) individuals from facilities management, and (9) power mobility prescribers. For the purposes of this research, progressive conditions were defined as those where ongoing deterioration would likely impact power mobility use, such as Parkinson's or Alzheimer's diseases. Nonprogressive conditions were defined as those that were relatively stable, such as spinal cord injuries or arthritis.

\section{Inclusion and Exclusion Criteria}

To be included in the study, power mobility usersdefined as individuals who used power mobility as their primary method of mobility-needed to have a minimum of 6 months experience with their power mobility device. Power mobility prescribers needed to have assessed a minimum of two clients for power mobility use. Other participants were to have had a minimum of 6 months experience with power mobility users. Although no formal cognitive or language testing was conducted, participants who were interested in participating in the study needed to have sufficient cognitive ability and English proficiency to be able to contact the principal investigator to arrange an interview and to give consent.

\section{Recruitment}

Participants were recruited by word of mouth and through posters placed within the residential facilities involved in the study. Table 1 describes those who participated in each round of the Delphi in terms of their membership in stakeholder groups and facilities. When a participant was not available for one stakeholder group from one facility, the stakeholder group was rounded out with participants from other facilities when available. Because no one from facilities management was willing to participate in the study, that stakeholder group was eliminated.

\section{Data Collection}

The research involved three rounds of feedback. Each round was developed in conjunction with all the authors of the study. The first round consisted of open-ended questions derived from the results of a qualitative study that explored perceptions of power mobility and power mobility safety within the facilities studied [16]. In the first round, for example, participants were asked to (1) identify principles upon which power mobility safety guidelines should be based, (2) define safe driving, and (3) indicate how power mobility safety should be assessed and how safety issues should be handled. Some of the prompts in the first round of the Delphi included questions such as "Who should be considered a potential power mobility user?" and "If someone is driving in an unsafe manner, what might be a reasonable consequence?"

In the second round of the Delphi, a subsequent Delphi questionnaire was created that summarized responses from the first round. Participants were asked to rate their agreement with each of the 225 items derived from the first round on a 7-point Likert scale, from 1 (strongly disagree) to 7 (strongly agree). Generally, items were verbatim participant statements. For example, participants 


\section{RESULTS}

As a basis for the development of client-centered guidelines, participants in the first round of the Delphi were first asked to indicate principles upon which decisions about power mobility safety should be made. A thematic analysis of these findings revealed eight overarching principles. In the second round of the Delphi, participants were asked to rate agreement with the principles that were developed (Table 2, under Items, Principles subsection). Table 2 describes the mean scores ( $1=$ strongly disagree and 7 = strongly agree) and the percentage moderately or strongly agreeing (scoring 6 or higher) for each item across all participants for the second and third rounds of the Delphi as available. One unusual principle was identified by participants in the first round of the Delphi, and one controversial principle was revisited in the third round of the Delphi. The first principle was whether "the guidelines should apply equally to those who owned their power chairs versus those who used facility ones." This item was proposed as an item for consideration by some Facility 1 residents who were concerned that power mobility users who owned their own chairs were treated preferentially over those who used facility chairs (e.g., had fewer restrictions on their wheelchair use and programming). Although it was indicated to participants in the second round of the Delphi that, from a legal perspective, competent individuals driving outside the facility in their own chairs were not under facility control, participants strongly supported the idea that the guidelines should apply equally to all users inside and outside the facility. The second principle, revisited in the third round, was whether "the guidelines should address the appropriateness of power mobility for residents who drove too slowly or blocked hallways.” In the third round, support for this item decreased.

\section{Clients Suitable for Power Mobility Trial}

Determining who should be considered for power mobility was contentious for participants. On one hand, participants described how power mobility users needed to have certain intellectual (ability to learn and respond appropriately) and physical (adequate vision and reliable motor function) capacities to be able to drive safely. On the other hand, examples were also given of individuals who were able to drive safely despite dementia, poor motor function, and/or legal blindness. For the second round, in an attempt to resolve this controversy, the fol- lowing statement was developed and Delphi participants were asked to indicate their agreement or disagreement with it: "In general, it seems that most residents could be considered for power mobility but that a more in-depth trial and training process is needed to decide whether those with cognitive, movement, or vision problems are safe to drive.” Out of 11 responding participants, 10 indicated support for this statement (91\%).

\section{Safe Driving}

When a definition of safe driving was being developed, two contentious elements were considered (Table 2, Items 9 and 10): (1) using an orange flag and (2) wearing an orange vest when driving outside.

\section{Ongoing Evaluation}

Because participants from Facility 1 were strongly opposed to yearly driving evaluations, all participants were asked to rerate this item in the third round of the Delphi (Table 2, Item 11). Some power mobility users felt this was an invasive measure, and prescribers indicated that it might not be feasible, given time constraints, and that it would not address problem situations that arise daily. Although the mean score fell, the percentage moderately or strongly agreeing remained relatively unchanged in the third round.

\section{Reasons to Deny Power Mobility Use}

Participants were asked to rate agreement with reasons to deny the use of power mobility following initial training (Table 2, Items 12 to 17). In the third round participants were asked to rerate two items: "are unable to avoid bumping into objects or damaging property" and "are unable to learn from their mistakes."

\section{Discontinuing Power Mobility Use}

Delphi participants were asked to respond to a number of controversial issues about the reasons to discontinue power mobility use (Table 2, Items 18 to 21). In the third round of the Delphi, participants were asked to rerate whether repeated incidents of damage to property or three serious incidents should be grounds for discontinuing power use. In Table 2, Items 22 to 24, participants indicated support for removing power mobility devices for increasing amounts of time for volitional problems, removing a wheelchair until individual deals with chemical dependency issues and, in some cases, permanent removal for individuals with progressive illnesses. 
JRRD, Volume 43, Number 2, 2006

A controversy arose about whether alcohol use while driving constituted a reason for discontinuing use. When asked, 25 percent of respondents supported a zero toler- ance position, whereas 75 percent of respondents indicated that a power mobility device should only be removed if alcohol use had impaired driving ability.

Table 2.

Mean and percentage agreement ratings from second and third rounds of Delphi with items for inclusion in power mobility safety guidelines.

\begin{tabular}{|c|c|c|c|c|}
\hline Item & \multicolumn{2}{|c|}{$\begin{array}{c}\text { Mean (1 = Strongly Disagree, } \\
7 \text { = Strongly Agree) }\end{array}$} & \multicolumn{2}{|c|}{$\begin{array}{c}\% \text { Moderately } \\
\text { or Strongly Agreeing }\end{array}$} \\
\hline \multicolumn{5}{|l|}{ Principles } \\
\hline $\begin{array}{l}\text { 2. A power mobility user's need for mobility is balanced with rights of } \\
\text { others for safety. }\end{array}$ & 6.4 & - & 90 & - \\
\hline 3. Some accidents will happen. & 6.5 & - & 90 & - \\
\hline $\begin{array}{l}\text { 4. Problem solving is emphasized to allow users to maintain their } \\
\text { mobility. }\end{array}$ & 6.4 & - & 90 & - \\
\hline $\begin{array}{l}\text { 5. Within the limits of these guidelines, residents have options about } \\
\text { their mobility. }\end{array}$ & 6.1 & - & 82 & - \\
\hline 6. The bureaucratic system is kept to a minimum. & 6.3 & - & 86 & - \\
\hline \multicolumn{5}{|l|}{ Elements of a Definition of Safe Driving } \\
\hline 9. Uses an orange flag (a small triangular flag on a $1 \mathrm{~m}$ fiberglass pole). & 5.1 & - & 50 & - \\
\hline $\begin{array}{l}\text { 10. Wears an orange vest when driving outside (a vest with reflective } \\
\text { tape). }\end{array}$ & 4.8 & - & 45 & - \\
\hline \multicolumn{5}{|l|}{ Ongoing Evaluation } \\
\hline 11. There should be yearly driving evaluations. & 5.1 & 4.6 & 62 & 63 \\
\hline
\end{tabular}

\section{Reasons to Deny Power Mobility Use}

The use of power mobility would be considered inappropriate for individuals who, despite modification to the power mobility device, the environment and/or driver education-

12. Use the wheelchair as a weapon.

13. Are unable to stop the power mobility device.

14. Have an accident as the result of alcohol or drug use.

15. Are unable to avoid bumping into others.

16. Are unable to learn from their mistakes.

17. Are unable to avoid bumping into objects or damaging property.

Discontinuing Power Mobility Use

Power mobility use will be discontinued-

18. After repeated incidents of running into objects and damaging property.

19. After no more than three serious incidents.

20. After repeated incidents of running into objects and damaging property.

21. Immediately, if the user has used the wheelchair as a weapon.

A power mobility device may need to be removed-

22. For increasing amounts of time for volitional problems.

23. Until an underlying problem, such as alcoholism, is dealt with.

24. Permanently, for some individuals with progressive illnesses.

*Cells with "-_" indicate that item was not rerated in third round of Delphi. 


\section{DISCUSSION}

Power mobility use is a key element to the independence of a small but significant number of individuals who live within a residential facility. Deterioration of driving skills or misuse of the privilege of power mobility can cause personal injury and damage to property and lead to conflicts among power mobility users and between power mobility users and other individuals, especially in shared living situations [16]. Many of these issues became apparent as participants worked to develop the power mobility safety guidelines.

\section{Principles}

Participants identified and supported a number of interesting principles upon which decisions about power mobility safety were to be made. The acknowledgment that "some accidents will happen" (Table 2, Principle 3) supports the idea of reasonable risk taking [12], rather than risk management, the approach in which institutions develop policies and procedures that eliminate risk (e.g., preventing the use of power mobility) [11]. Support for reasonable risk taking is comforting for prescribers in long-term care settings who need to balance a user's need for mobility with the safety of those around them.

The principle that the guidelines should apply equally "to those who own their chairs and to those who use facility chairs" (Table 2, Principle 7) was strongly supported by participants despite concerns raised that it might not be legally enforceable outside the facility. This support seems to indicate the participants' need for equal treatment under the guidelines outweighed legal considerations of property ownership. Perhaps most interestingly, some participants indicated that "residents who drive too slowly" should not have access to power mobility and suggested it as an overarching principle for the guidelines (Table 2, Principle 8). Participants, particularly at Facility 1, noted that these slow drivers, whose chairs had been programmed to operate at a reduced speed to promote safety, made mobility difficult for other users. As noted in the first phase of the study [16,] problems traveling within the facility, because of hallways cluttered with equipment and blocked by slow drivers, sometimes created frustration that could contribute to dangerous driving behaviors on the part of others, similar to "road rage" attributed to automobile drivers. Ironically, therapists' interventions to promote safe driving with some individuals could have the opposite effect on other drivers in facilities, which were designed without enough space for equipment storage. In this regard, apparently in some instances, architectural constraints of residential facilities that may be beyond the control of the therapist or client may contribute to problems with power mobility safety.

\section{Clients Suitable for Power Mobility Trial}

When considering which residents might be considered for a trial of power mobility, many participants seemed initially to want to exclude individuals on a diagnosis-specific basis. In the end, however, the panel agreed on a much more inclusive method of evaluating power mobility based on function. This decision not only acknowledges the disjuncture between diagnosis and function but also agrees with some recent research. For example, research has found that some individuals with right-sided neglect following left-sided cerebral vascular accidents have demonstrated (1) improvement in driving ability with practice and (2) the ability to drive safely [23].

\section{Elements of a Definition of Safe Driving}

In discussing the notion of safe driving, a large number of participants-particularly those from or affiliated with Facilities 2 and 3-indicated that the use of orange safety vests when driving outside and orange flags should be incorporated into a definition of safe driving. Although such devices probably make users more visible, they can also increase the stigma already associated with power mobility use [16], a concern that was voiced particularly by Facility 1 residents. At the heart of this debate is the need to balance an individual's freedom to take risks with the need for enforced use of safety measures. As well, a question remains whether such a requirement would represent a form of discrimination against people with mobility impairments [24-26]. Such stigmatization may have a psychological impact on users and may lead to feelings of anxiety and depression, decreased device use and, ultimately, reduced participation in daily activity [27].

\section{Reasons to Deny Power Mobility Use}

When considering what constituted a reason to restrict power mobility use following initial training, participants agreed on a number of items. All participants strongly or moderately agreed that the use of the wheelchair as a weapon should not be tolerated. Although this might seem like a straightforward suggestion, determining 
if a chair was used as a weapon requires judging intent, which may be difficult when relying on the perceptions of those involved in the incident. Participants also indicated that power mobility was inappropriate for those who could not stop their chairs and, more controversially, for those who were unable to learn from their mistakes. Although this latter trait may intuitively seem sensible, it seems to disregard the notion that wheelchair or environmental modification might make power mobility driving safe for some individuals who were, in fact, unable to learn from their mistakes. Therefore, excluding individuals from driving who are unable to learn from their mistakes may be misguided if the desired outcome is safe driving.

Concern about damage to property was a contentious issue throughout the research. Although damage to property was a less important concern than personal injury for participants, participants strongly indicated that incidents of damage to property could exclude potential users from power mobility use and that repeated incidents could be grounds to have the device removed. Ultimately, however, this nuance seemed to have been lost by the end of the Delphi process.

\section{Discontinuing Power Mobility Use}

Although discontinuing power mobility use was not a preferred intervention, a consensus existed about when power mobility should be discontinued. Participants indicated they had no tolerance for the use of power mobility as a weapon and for driving while impaired [16]. Although the use of small amounts of alcohol while driving was generally tolerated, a minority felt a no tolerance, abstinence-type policy should be established. While the former idea was consistent with current societal beliefs around drinking and driving, the latter might have been supported as a matter of pragmatics in that, without special equipment, the level of intoxication is difficult to determine. Participants also recognized that abuse of alcohol might preclude the use of power mobility for some individuals.

Participants generally supported the idea of progressive punishment when dealing with volitional issues (speeding, intentionally bumping into others, etc.), which is a long-standing tradition within the legal system. Although some participants indicated that a power mobility device should never be removed permanently (akin to a faint hope clause), the majority indicated that discon- tinuing the use of power mobility for individuals with progressive conditions might be necessary.

\section{Limitations of the Study}

The results of this study are specific for long-term residential care settings in a specific health region, which may limit the transferability of these findings to other facilities within Canada and other countries. Because the facilities involved in the study provided extended care, the power mobility safety issues addressed in these guidelines may be different from those in other settings, such individuals living in the community.

The fact that participants self-selected to participate means that the composition of the Delphi panel was different than if panelists had been individually invited to participate. As well, a differential rate of attrition occurred throughout the project, which varied among stakeholder groups and facilities. This meant that, for the final round, only a small number of participants represented Facility 1, which might have influenced the overall percentage of those moderately or strongly agreeing, especially given the difference in average age between Facility 1 and Facilities 2 and 3.

\section{Use of Delphi Method}

The Delphi method had both advantages and disadvantages in this study. The primary advantage was that the use of anonymous questionnaires allowed residents to participate as equals with others who had more power within the facilities. One of the difficulties with the use of the Delphi as a methodology, however, was that, because it was a pen-and-paper method of communicating ideas, presenting concepts that were complex was difficult. For example, although participants would describe good reasons for making decisions that went against that of the majority, the Delphi method made communicating these ideas simply and understandably quite difficult. Another issue was that different opinions existed between facilities around issues such as yearly driving evaluations, slow drivers, and the use of orange flags and/or vests for outside mobility. These differences meant the consensus we desired was more difficult to achieve on some issues.

Given the amount of data created during the first and second round of the Delphi, rating all items presented in the second round became onerous for participants, and so the third round only included areas of controversy. This means that the veracity of some items was not rechecked and may have changed in subsequent rounds. 


\section{Future Research Directions}

A number of areas for future research are suggested by the findings of this study. Projects could be conducted to explore whether the findings of this study may be generalized to a regional or national level. Prospective studies could examine many of the guideline items, such as (1) whether the reasons to deny power mobility have predictive validity and (2) whether any of the safety solutions and interventions suggested in the guidelines actually lead to increased power mobility safety. Studies could also assess if the introduction of the guidelines leads to increased staff and/or user satisfaction with the process of handling power mobility safety issues. Research to address the reliability of these guidelines is currently under way.

\section{CONCLUSION}

This article describes some of the salient and contentious findings of a research project to develop clientcentered power mobility safety guidelines through the use of a modified Delphi method. Some of the issues explored in this article include questions of who should be considered for power mobility, who should be deemed incapable, and when power mobility use should be discontinued. These issues offer insight into the complexity and difficulties that may be encountered when dealing with power mobility safety issues within a residential facility setting. These findings indicate gray areas that need to be considered when similar guidelines for other settings are developed. Ultimately, we hope that such guidelines will allow users of power mobility living in long-term facilities to have power mobility safety concerns addressed in an evidenced-based and equitable manner.

\section{ACKNOWLEDGMENTS}

We deeply appreciate the help of all of those individuals who took part in the Delphi process to develop these guidelines. We would also like to thank our research assistant Natasha Tam for her work on the study.

This material was based on work supported by the Vancouver Foundation, grant BCM01-0090, and the Vancouver Coastal Health Research Institute; salary support was provided for Dr. Miller by the Canadian Institutes of
Health Research and the Michael Smith Foundation for Heath Research.

A portion of these findings has been presented at the 20th International Seating Symposium in Vancouver, British Columbia, Canada, March 2004.

The authors have declared that no competing interests exist.

\section{REFERENCES}

1. Evans R. The effect of electrically powered indoor/outdoor wheelchairs on occupation: A study of users' views. Br J Occup Ther. 2000;63(11):547-53.

2. Bottos M, Bolcati C, Sciuto L, Ruggeri C, Feliciangeli A. Powered wheelchairs and independence in young children with tetraplegia. Dev Med Child Neurol. 2001;43(11):769-77. [PMID: 11730152]

3. Frank AO, Ward J, Orwell NJ, McCullagh C, Belcher M. Introduction of a new NHS electric-powered indoor/ outdoor chair (EPIOC) service: Benefits, risks and implications for prescribers. Clin Rehabil. 2000;14(6):665-73.

[PMID: 11128743]

4. Brandt A. The power of independence. Rehab Manage: Interdiscip J Rehabil. 2001;14(8):54,56,58.

5. Miles-Tapping C, MacDonald LJ. Lifestyle implications of power mobility. Phys Occup Ther Geriatr. 1994;12(4):31-49.

6. Dawson D, Chan R, Kaiserman E. Development of the power-mobility indoor driving assessment for residents of long-term care facilities: A preliminary report. Can J Occup Ther. 1994;61(5):269-76.

7. Reed RL, Yochum K, Schloss M. Platform motorized wheelchairs in congregate care centers: A survey of usage and safety. Arch Phys Med Rehabil. 1993;74(1):101-3. [PMID: 8420509]

8. Cooper RA, Cooper R. Trends and issues in wheeled mobility technologies. In: Space Requirements for Wheeled Mobility Workshop; 2003 Oct 9-11; Buffalo (NY).

9. Statistics Canada. Population projections for Canada provinces and territories, 2005 to 2031. Catalogue No. 91-520XIE. Ottowa, Ontario, Canada, 2005. Available from: http:/ /www.statcan.ca/english/freepub/91-520-XIE

10. Ummat S, Kirby SL. Nonfatal wheelchair-related accidents reported to the National Electronic Injury Surveillance System. Am J Phys Med Rehabil. 1994;73(3):163-67. [PMID: 8198772]

11. Townsend E. Good intentions overruled: A critique of empowerment in the routine organization of mental health services. Toronto (Canada): University of Toronto Press; 1998. 
12. Townsend E. Enabling occupation: An occupational therapy perspective. Ottawa (Canada): Canadian Association of Occupational Therapists Publications ACE; 1997.

13. Letts L, Dawson D, Kaiserman-Goldenstein E. Development of the power-mobility community driving assessment. Can J Rehabil. 1998;11(3):123-29.

14. Law M, Baptiste S, Mills J. Client-centred practice: What does it mean and does it make a difference? Can J Occup Ther. 1995;62(5):250-57. [PMID: 10152881]

15. Webber S, Laminam K. A region wide power mobility program. In: Mindful Care II. A Psychogeriatric Conference 2004; 2004 Sep 30-Oct 1; Brandon (Canada).

16. Mortenson WB, Miller WC, Boily J, Steele B, Odell L, Crawford EM, Desharnais G. Perceptions of power mobility use and safety within residential facilities. Can J Occup Ther. 2005:72(3):142-52. [PMID: 15988961]

17. Department of National Health and Welfare and Canadian Association of Occupational Therapists. Guidelines for the client-centred practice of occupational therapy. Cat. H3933/1983E. Ottawa (Canada): Department of National Health and Welfare and Canadian Association of Occupational Therapists; 1983.

18. Department of National Health and Welfare and Canadian Association of Occupational Therapists. Intervention guidelines for the client-centred practice of occupational therapy. Cat. H39-100/1986E. Ottawa (Canada): Department of National Health and Welfare and Canadian Association of Occupational Therapists; 1983.
19. Zinn J. Use of the Delphi panel method to develop consensus on laboratory performance indicators. Clin Lab Manage Rev. 1998;12(2):97-105. [PMID: 10178715]

20. Hicks CN. The Delphi technique. In: Hicks CN, editor. Research methods for clinical therapists: Applied project design and analysis. 3rd ed. Toronto (Canada): Churchill Livingstone; 1999. p. 243-49.

21. Cretin S, Margolis CZ, editors. Implementing clinical practice guidelines. Hoboken (NJ): Jossey-Bass; 1999.

22. Hammersley M, Atkinson P. Ethnography: Principles in practice. 2nd ed. New York (NY): Routledge; 1995.

23. Dawson J, Thornton H. Can patients with unilateral neglect following stroke drive electrically powered wheelchairs? Br J Occup Ther. 2003;66(11):496-504.

24. Fine SM, Asch A. Disability beyond stigma: Social interaction, discrimination, and activism. J Soc Issues. 1988; 44(1):3-21.

25. Zola IK. Depictions of disability-Metaphor, message, and medium in the media: A research and political agenda. Soc Sci J. 1985;22(4):5-17.

26. Zola IK. Bringing our bodies and ourselves back in: Reflections on a past, present and future "medical sociology.” J Health Soc Behav. 1991;32(1):1-16.

27. Bates PS, Spencer JC, Young ME, Rintala DH. Assistive technology and the newly disabled adult: Adaptation to wheelchair use. Am J Occup Ther. 1993;47(11):1014-21. [PMID: 8279496]

Submitted for publication January 31, 2005. Accepted in revised form October 25, 2005. 